\title{
Experimental evaluation of floor slab contribution in mitigating progressive collapse of steel structures
}

\author{
M. Hadjioannou ${ }^{1}$, S. Donahue ${ }^{1}$, E. B. Williamson ${ }^{1}$, \\ M. D. Engelhardt ${ }^{1}$, B. Izzuddin ${ }^{2}$, D. Nethercot ${ }^{2}$, \\ H. Zolghadrzadehjahromi ${ }^{2}$, D. Stevens ${ }^{3}$, K. Marchand ${ }^{3}$ \\ \& M. Waggoner ${ }^{4}$ \\ ${ }^{I}$ Civil, Architectural and Environmental Engineering Department, \\ Cockrell School of Engineering Department, \\ University of Texas at Austin, USA \\ ${ }^{2}$ Imperial College, London, UK \\ ${ }^{3}$ Protection Engineering Consultants, San Antonio, Texas, USA \\ ${ }^{4}$ Walter P. Moore, Austin, Texas, USA
}

\begin{abstract}
As a result of several high-profile terrorist attacks against buildings in recent years, mitigating progressive structural collapse has been of particular interest to the structural engineering community. Previous research studies have focused on the impact of an individual column failure on the overall stability of a structure. These studies have relied mostly on computational investigations and experimental tests on individual components. Few studies have been done to predict the behavior of floor slabs above a failed column, and the computational tools used have not been validated against experimental results. The research program presented in this paper extends prior work in this area by testing specimens that include all structural components of a typical floor system in a prototypical steel-framed structure. In total, six full-scale tests will be performed, including three interior 2-bay $\times 2$-bay specimens and three exterior 2 -bay $\times 1$ bay specimens. In all tests, the mid-span column will be removed statically while the slab is loaded with the recommended extreme event design load. The slab consists of corrugated decking with lightly reinforced concrete on top that is connected to the floor beams through shear studs and is consistent with typical
\end{abstract}


building practices in the US. The first test is planned for the summer of 2012. The extensive computational analyses that have been done so far indicate the significant contribution the slab has in sustaining overall building stability and mitigating collapse. Initial analysis results show that the contribution of the corrugated decking acting compositely with the concrete slab is significantly greater than that of the floor beam grillage. The significant contribution of the corrugated decking is attributed to the membrane forces that are developed while the deflections increase. Preliminary analyses suggest that the slab in the test structure can sustain the removal of the mid-span column without collapsing. These models, however, require assumptions that must be validated against test data. Therefore, results from the tests will provide valuable information for validating analysis models and developing recommendations for improving current design practice.

Keywords: progressive collapse, disproportionate collapse, composite floor slabs.

\section{Introduction}

In steel-framed buildings, concrete floor slabs are typically designed to act compositely with the steel beams, reducing the required steel member sizes. Corrugated decking acts as a permanent formwork for the concrete slab. The integrated response of the floor system components reduces both the costs and the time of construction, making composite slabs a popular floor system in steel structures.

The beneficial contribution of composite floor slabs in steel buildings to enhance stability and lateral resistance has been previously identified by various research studies and is attributed mainly to the large in-plane stiffness of such slabs. Many of these research studies have been incorporated into design codes such as Eurocode 3 [1], Eurocode 8 [2], and AISC construction manual [3]. The contribution of composite floor systems to the progressive collapse resistance of steel-framed buildings, however, is still unclear. The need to better understand structural collapse phenomena has become evident in recent years following several high-profile terrorist attacks around the world, such as the destruction of the Alfred P. Murrah Federal Building in 1995 and the collapse of the World Trade Center towers in 2001.

Disproportionate collapse (also known as progressive collapse) occurs when an initial local failure spreads progressively to nearby intact elements. The loads carried by the failed elements need to be redistributed to intact elements in the vicinity of the collapsed elements. In the case where the structure is unable to redistribute these loads, collapse is expected, resulting in fatalities and financial consequences. In the case where these loads are successfully redistributed, the failure is localized, and the rest of the structure usually remains largely unaffected.

Experimental work on steel buildings with composite slabs is limited. The only experimental work done that is representative of a typical composite floor system was by Astaneh-Asl et al. [4], where they examined a 2-bay $\times 1$-bay 
portion of a composite slab after the sudden removal of a mid-span column. The specimen tested was representative of a section of the perimeter bays of a building. The researchers concluded that the structure was able to sustain the immediate column loss, at least for the particular case they studied. The current research program combines both computational and experimental work. A column removal scenario is considered as a potential collapse initiating event as described in the current UFC [5] and GSA [6] guidelines. First, a 2-bay $\times 2$-bay section of a composite floor slab, representative of an interior section of a building and consistent with typical US building practices, is modeled using detailed finite element simulations. The response of the slab is examined after removal of the mid-span column. The predicted response is then compared with a full-scale test of the same size. Second, similar computational and experimental work is done for a 2-bay $\times 1$-bay section of a composite floor slab, representative of a perimeter section of a building. This process will identify the weakest components of the floor system. Additionally, another series of tests includes improvements based on observations and US Department of Defense progressive collapse provisions [5]. This paper focuses on the former series of tests for an interior 2-bay $\times 2$-bay section of a building.

Two key areas are investigated: (1) the ability of state-of-the-art computational tools to predict the collapse behavior of composite floor slabs, and (2) identification of the components that help mitigate progressive collapse along with the weak components that possibly need to be enhanced. It is expected that findings from the test program will help inform decisions for improving computational tools used to simulate collapse. In addition, design recommendations to enhance the resiliency of steel-framed buildings will be proposed. This experimental program is expected to give a better understanding of the progressive collapse behavior of steel-framed buildings and produce detailed data on floor system response to a column loss scenario.

\section{Previous research}

\subsection{Slab contribution}

Research studies on the collapse behavior of steel-framed buildings have mainly focused on computational simulations and experimental tests of individual components [7-9]. These efforts are valuable because they provide a good understanding of individual component behavior under large deformations. There is strong evidence, however, that when all components of a structure, such as the floor slabs, are taken into consideration, the behavior is not consistent with the response obtained from an individual connection or component. When the slab undergoes large deformations, membrane forces develop. These forces contribute to the integrity of a structure after the failure of a vertical element [10].

Research regarding the contribution of slabs in the mitigation of progressive collapse has mainly focused on reinforced concrete (RC) slabs. Under normal loading conditions, flexural action is the primary load resisting mechanism. For a 
column removal scenario, the deflections in the slab increase, and the primary load resisting mechanism transitions from flexural response to membrane response. The slab can potentially redistribute the loads to nearby intact elements, mitigating progressive collapse. In the central portion of the slab, tensile stresses are developed; at the perimeter, the stresses are compressive. The region of the slab that is either in tension or compression depends on the boundary conditions. In the case where the edges of the slab are unrestrained for in-plane translation, they can be pulled inwards, causing the formation of a compression ring around the perimeter of the slab, which creates a selfequilibrating system of forces. When the edges are restrained for in-plane translation, the tension zone is larger than the unrestrained case and extends around the perimeter because equilibrating forces develop along the perimeter restraints. In both cases, the tensile stresses are carried by the slab's reinforcement. Some notable studies include the work of Park [11] for slabs with restrained edges, Hawkins and Mitchell [12] and Mitchell and Cook [13] for mitigating progressive collapse of slabs, and the work of Brotchie and Holley [14] for membrane action in slabs.

Sadek et al. [7, 15] have verified through computational modeling of composite floor systems that the contribution of the concrete slab with corrugated decking is significant, whereas the contribution of the steel beam grillage is small. The membrane action in the slab helps redistribute loads to the unaffected elements of the building [16-18]. Unlike buildings with reinforced concrete slabs, floor systems in composite steel-framed structures typically include limited amounts of reinforcing steel. Nonetheless, the corrugated decking at the bottom of composite slabs provides a relatively large amount of steel that can potentially contribute to the development of membrane action in composite slabs [15].

Aside from the experimental work by Astaneh-Asl et al. [4] previously described, other notable studies are the work of Huang et al. [19,20], Bailey et al. [21]. Those studies primarily focus on the collapse resistance of composite slab systems at elevated temperatures.

\subsection{Design guidelines for progressive collapse}

UFC 4-023-03 [5] provides guidance for the design of buildings to resist progressive collapse. Those guidelines are based mainly on analytical and computational studies, and the general approach relies on the development of "tie forces." The basic idea is to mechanically "tie together" the building using three horizontal ties: longitudinal, transverse, and peripheral. Acceptable floor systems that this concept is applicable to are cast-in-place concrete, composite decks, and precast concrete floor planks with a concrete topping slab. The tie forces are usually carried by the reinforcing steel in the floor slab. To meet the tie force requirements, it is often necessary to include additional reinforcing steel than would otherwise be needed. Although these guidelines seem reasonable and effective, no experimental tests have been performed yet to verify that this approach enhances the resiliency of buildings. Regarding composite floor systems, the current guidelines [5] neglect the strength provided by the 
corrugated decking, which has been shown to contribute significantly in resisting progressive collapse $[4,15]$.

\section{Experimental program}

A series of tests will be performed to evaluate the response of composite floor systems under a column removal scenario. The experimental setup allows for testing both interior and perimeter column loss events. The first test for a 2-bay $x$ 2-bay section, representative of the interior bays of a building, will be performed this summer.

\subsection{Prototype building}

A prototype building designed by Walter P Moore (WPM) was used as the base design for the test specimens. The building is a typical office building with a steel-framed structure that uses simple connections. A concrete floor slab is poured over corrugated steel decking and acts compositely with steel beams and girders through shear studs. The design loads, connection types, and construction details match those found in current buildings constructed in the US. Due to budget limitations, the spans of the test specimens are smaller than those of typical office buildings, but the member sizes and connection strengths are consistent with those of the WPM prototype design.

\subsection{Boundary conditions}

Because the test specimens are either interior or exterior portions of the prototype building, the boundary conditions at the perimeter of these portions have been simulated so that they properly represent the restraint provided by the adjacent bays. To achieve these conditions, a relatively stiff restraining beam that circumscribes the slab was designed to simulate the relatively large in-plane stiffness and strength that the adjacent bays provide. For design purposes, because of the uncertainty associated with the location where a column is assumed to fail, the number of surrounding bays varies. As such, the exact lateral stiffness that should be provided by the restraining beam cannot be specified precisely. Computational analyses are presented in Section 4.2.2 and demonstrate the effectiveness of the restraining beam concept in capturing the response of the prototype building. Figure 1 shows the test frame with the restraining beam in place.

\subsection{Test procedure}

All test specimens will be tested under a column loss scenario. That column will be initially supported during the construction of the test specimens (Figure 1). Then, additional load will be applied to the top of the floor slab. The applied load will be consistent with the UFC-recommended collapse design load [5]. The actuator used to represent the failed column will be released during the test until 


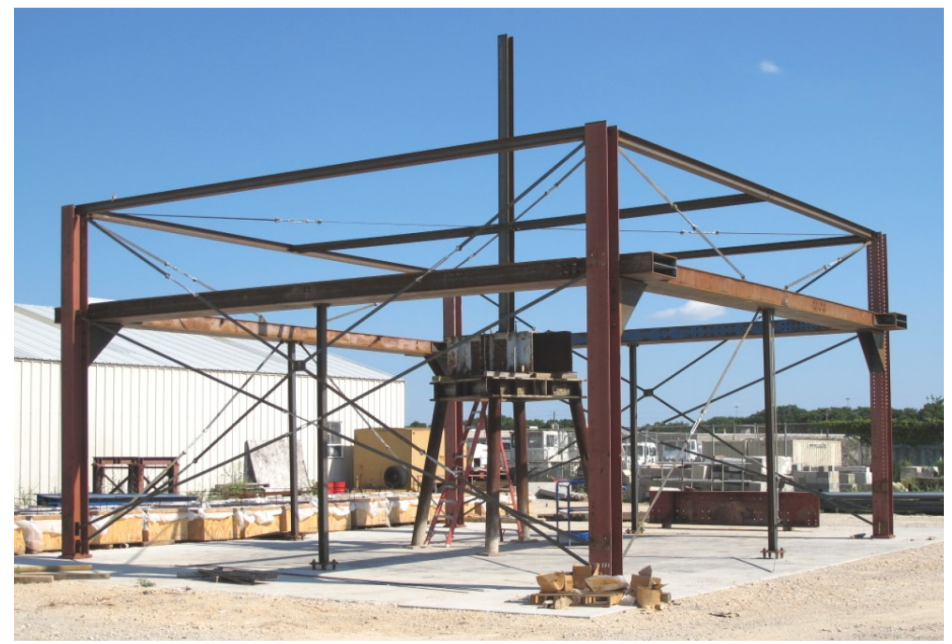

Figure 1: The test frame and the restraining beam.

the vertical reaction is zero, indicating that the floor slab is in equilibrium without the existence of the center column. Figure 2 shows a schematic representation of the test procedure.

All tests will be performed under static conditions to obtain a detailed understanding of the behavior of the floor slab under large deformations. This slow unloading rate will allow the research team to study the various types of response mechanisms that occur during column removal.

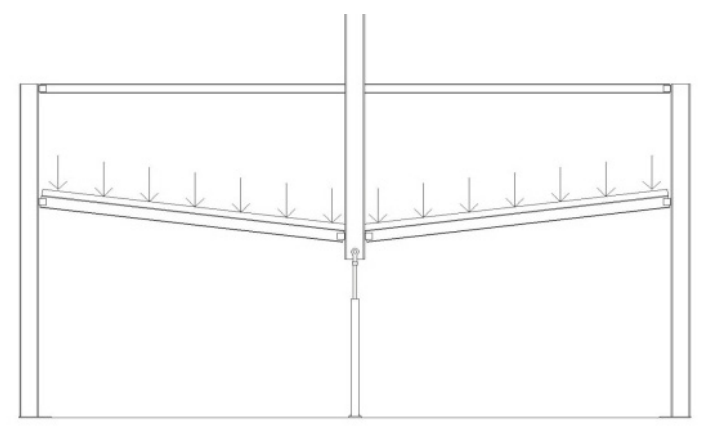

Figure 2: $\quad$ Lowering of central column to simulate column loss.

\section{Computational analyses}

The computational studies currently focus on the response of the first test specimen, which is for an interior column loss scenario. The specimen is representative of typical construction and does not include any special design details for mitigating progressive collapse 


\subsection{Modeling of bolted connections}

The first test specimen includes mainly double angle and shear tab connections, which are commonly used in composite floor slab construction. Before modeling the full slab system, both connection types were modeled and compared to experimental data to evaluate the ability of the computational tools to predict their response. For the current paper, due to space limitations, focus is given to double angle connections. Two finite element (FE) models were used; detailed and reduced. In the former, each part of the connection (i.e. bolts, angles, beams) was modeled explicitly using three-dimensional elements based on the guidelines of Selamet and Garlock [22] and those of Main and Sadek [23]. In the latter, each bolt was substituted with a non-linear spring that has the same loaddisplacement response with every bolt in the direction that was loaded, according to the models given in Eurocode 3 [1] and the proposed model of Rex and Easterling [24].

\subsubsection{Double angle connections}

Lewitt et al. [25] performed a series of tests to evaluate the response of various connections. Their specimen FK-3 (Figure 3(a)) is a double angle beam-tocolumn connection similar to the connection that is being used in the test specimens. The same connection was modeled with both detailed (Figure 3(b)) and reduced finite elements.

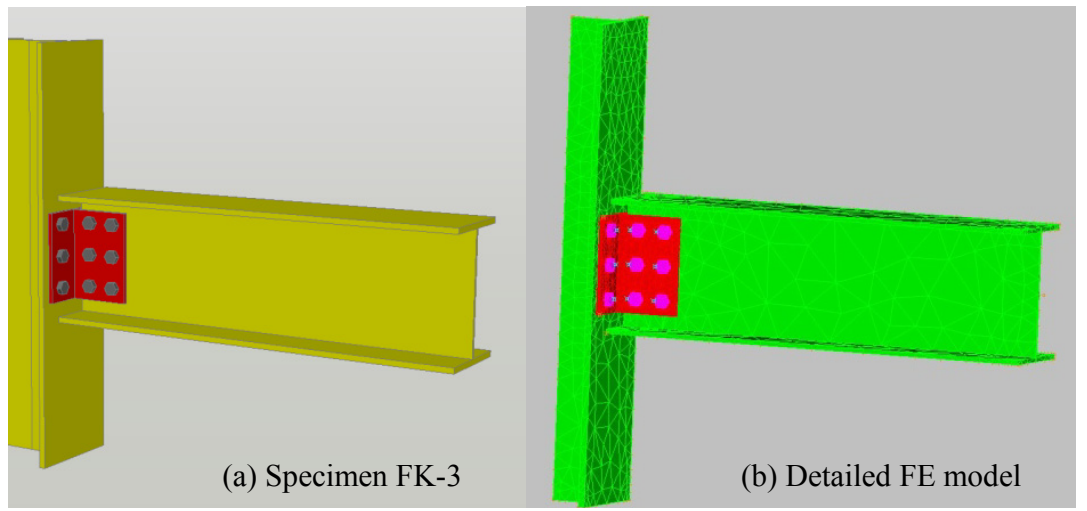

Figure 3: Double angle connection test specimen of Lewitt et al. [25].

The predicted response was compared with the experimental data. Figure 4 shows the comparison of the two FE models with the experimental curve. Both modeling methods predict the response of the connection with good accuracy. 


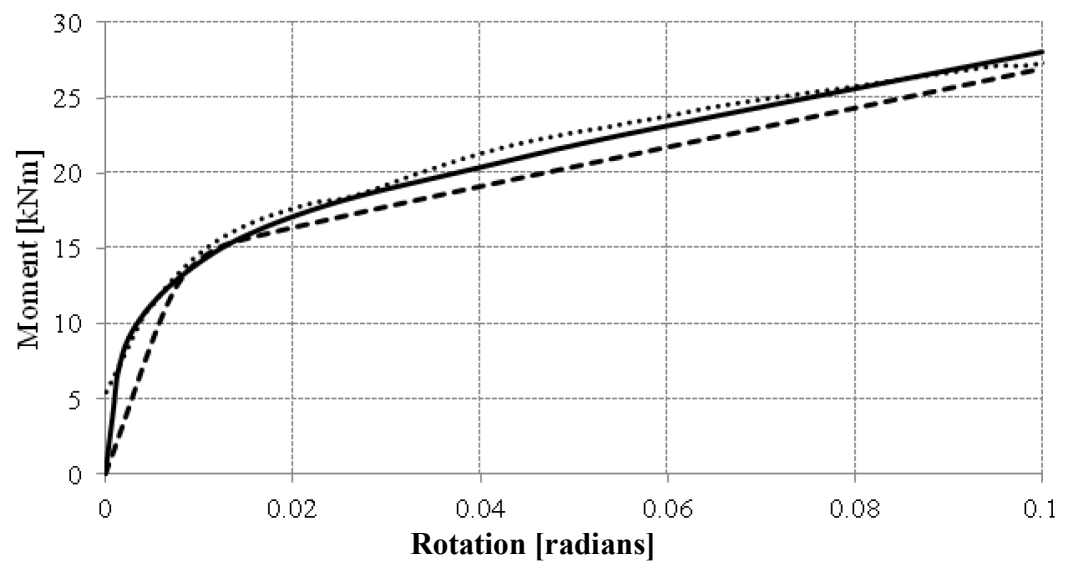

— Test data $\quad$......... Detailed model $\quad$ - - - - Reduced model

Figure 4: Moment-rotation curves for double angle connection.

\subsection{Composite floor slab response}

\subsubsection{Component contributions}

Analyses were performed to predict the response of the floor slab and to evaluate the individual component contributions under a column loss scenario. Three different models were considered: (1) the bare steel frame (i.e., the restraining beam, main girders, and secondary beams only); (2) the restraining beam with corrugated decking and the concrete slab (also referred to as the "ribbed slab" model); and (3) all the components of the floor system. All models were loaded with a concentrated vertical force at the location of the central column (i.e., the column that is assumed to fail). Figure 5 shows the load-displacement curves for all three cases. The contribution of the bare steel frame is negligible when compared with the contribution of the ribbed slab. Notably, when the steel grillage and ribbed slab are connected using shear studs, forming a fully composite floor system, the response is not just the summation of the responses of the two other models. The composite action between the floor beams and the concrete slab increases the capacity of the floor system. For the case of the bare steel frame, it is predicted that the first component failure will occur at a vertical displacement of approximately $0.45 \mathrm{~m}$, whereas the predicted value is $0.22 \mathrm{~m}$ for the fully composite floor. The failure is predicted to occur at the main girder to central column connection under bearing/tear out failure of the beam web. 


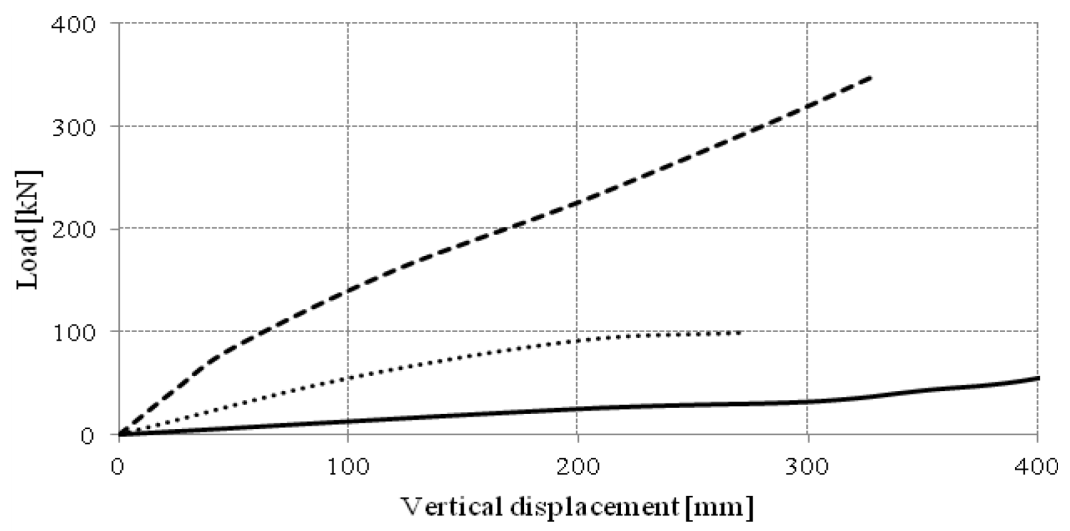

— Bare steel frame …..... Ribbed slab - --- Fully composite floor system

Figure 5: $\quad$ Response of the floor slab.

\subsubsection{Boundary conditions}

To evaluate the effect of the restraining beam, a series of analyses was performed for the fully composite floor system with different boundary conditions. Four different cases were considered: (1) the restraining beam (Figure 1) designed for the test program; (2) slab edges fully restrained (i.e., no in-plane displacement allowed); (3) inclusion of the adjacent bays to the portion of the slab under investigation; and (4) slab edges free to move (i.e., no in-plane edge restraints). The load pattern used in these analyses was the same as the one planned for the
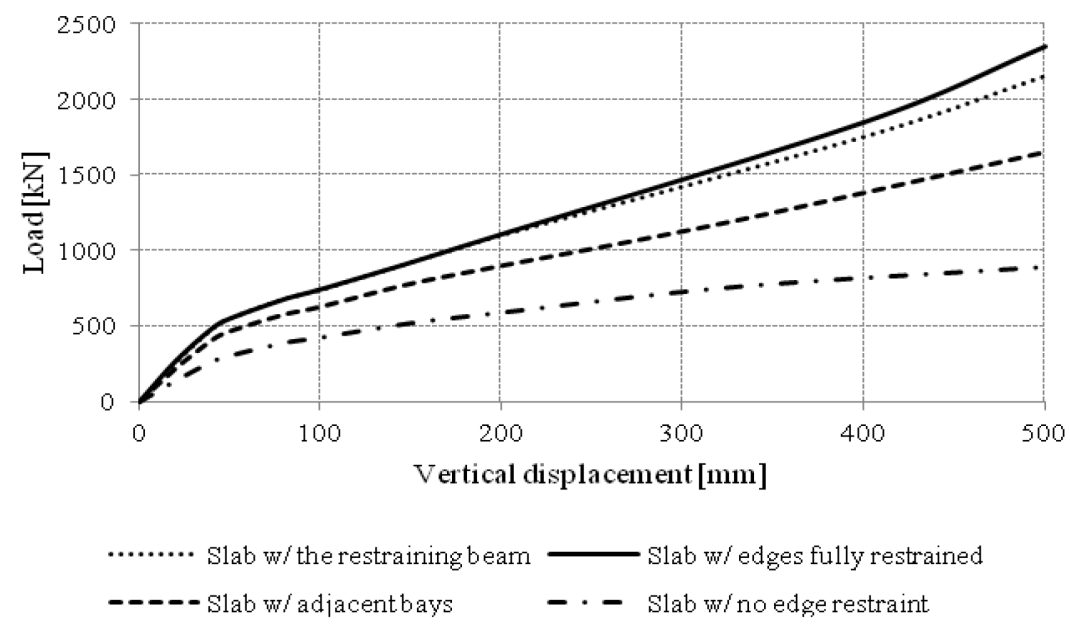

Figure 6: Effect of different boundary conditions on the response of the fully composite floor system. 
experimental tests (Section 3.3). Figure 6 shows the response of the fully composite floor system with the different boundary conditions. The response is bounded between the cases where the slab edges are fully restrained and unrestrained. The unrestrained slab does not allow for the development of catenary forces; therefore, the load that the slab can carry is considerably lower than the restrained case. Comparing the latter with the case where the restraining beam is present, it can be seen that this provides enough planar restraint so that catenary forces can be developed. The capacity of the floor slab with the adjacent bays present is slightly lower than for the case of the restraining beam, which implies the restraining beam might over-restrain the slab relative to what might be expected in an actual structure. Considering, however, the uncertainty associated with the location of an initiating column failure, the restraint that may exist in an actual structure is uncertain. Hence, the test setup used for the experimental program is considered appropriate for meeting the objectives of the research.

For the case where the restraining beam is present, the first component failure is expected to occur at a vertical displacement of approximately $220 \mathrm{~mm}$, which corresponds to a distributed load of approximately $13 \mathrm{kN} / \mathrm{m}^{2}$. This level of displacement corresponds to nearly two times the UFC [5] recommended design load for progressive collapse.

\section{Discussion/future work}

The experimental tests that will be performed during this research program are expected to give valuable information regarding the resiliency of composite floor systems under a column removal scenario. Previous research has demonstrated the considerable amount of reserve capacity that these floor systems have, something that is confirmed from the computational studies that have been performed to date. Experimental data are needed, however, to validate these predictions and to characterize the response mechanisms that control response during a collapse event. With such data, limitations of the computational models can be identified so that they can be improved. Based on the analyses performed thus far, the interior 2-bay $\times 2$-bay test specimen, which is representative of an interior portion of a building design without any provisions for progressive collapse, will be able to sustain a central column loss scenario under static unloading conditions. Future tests will consider other design parameters and column loss scenarios. Computational modeling will continue throughout the research program to compliment the experimental work.

\section{Acknowledgements}

This material is based upon work supported by the Science and Technology Directorate, US Department of Homeland Security under Award Number: 2010ST-108-000014. The authors thank the Department of Homeland Security (DHS) for their support of this research program. The views and conclusions contained in this document are those of the authors and should not be interpreted as 
necessarily representing official policies, either expressed or implied, of the US Department of Homeland Security.

\section{References}

[1] E.C.f. Standardization, Eurocode 3: Design of Steel Structures, 2005.

[2] E.C.f. Standardization, Eurocode 8: Design of structures for earthquake resistance.

[3] I. American Institute of Steel Construction, Specification for Structural Steel Buildings, in, American Institute of Steel Construction, Inc, Chicago, IL, 2005.

[4] A. Astaneh-Asl, B. Jones, Y. Zhao, R. Hwa, Progressive Collapse Resistance of Steel Building Floors, in, University of California at Berkeley, 2001.

[5] N.I.o.B. Sciences, UFC 4-023-03 Design of Buildings to Resist Progressive Collapse, in, Department of Defense, 2009.

[6] U.S.G.S. Administration, Progressive Collapse Analysis and Design Guidelines for New Federal Office Buildings and Major Modernization Projects, in, 2003.

[7] F. Sadek, J.A. Main, H.S. Lew, S.D. Robert, V.P. Chiarito, S. El-Tawil, An Experimental and Computational Study of Steel Moment Connections under a Column Removal Scenario, in, National Institute of Standards and Technology, Gaithersburg, MD, 2010.

[8] F.H. Sadek, J.A. Main, H.S. Lew, Y. Bao, Testing and Analysis of Steel and Concrete Beam-Column Assemblies under a Column Removal Scenario, Journal of Structural Engineering, 137, 881-892, 2011.

[9] A. Tsitos, G. Mosqueda, A. Filiatrault, A.M. Reinhorn, Experimental Investigation of Progressive Collapse of Steel Frames Under Multi-hazard Extreme Loading, in: The 14th World Conference on Earthquake Engineering, Beijing, China, 2008.

[10] H. Li, S. El-Tawil, Three-Dimensional Effects in Progressive Collapse Modeling, in: Structures Congress 2011, ASCE, Las Vegas, NV, pp. 28292839, 2011.

[11] R. Park, Tensile Membrane Behavior of Uniformly Loaded Rectangular Reinforced Concrete Slabs with Fully Restrained Edges, Magazine of Concrete Research, 16, 39-44, 1964.

[12] N.M. Hawkins, D. Mitchell, Progressive Collapse of Flat Plate Structures, Journal of American Concrete Institute, 76, 775-808, 1979.

[13] D. Mitchell, W. Cook, Preventing Progressive Collapse of Slab Structures, Journal of Structural Engineering, 110, 1513-1532. 1984.

[14] J.F. Brotchie, M.J. Holley, Membrane Action in Slabs, ACI SP-30, 30, 1971.

[15] F.H. Sadek, S. El-Tawil, H.S. Lew, Robustness of Composite Floor Systems with Shear Connections: Modelling, Simulation, and Evaluation, Journal of Structural Engineering, 134, 1717-1725, 2008. 
[16] C.G. Bailey, Membrane action of slab/beam composite floor systems in fire, Engineering Structures, 26, 1691-1703, 2004.

[17] C.G. Bailey, Membrane Action of Unrestrained Lightly Reinforced Concrete Slabs at Large Displacements, Engineering Structures, 23, 470483, 2001.

[18] P.X. Dat, T.K. Hai, Membrane actions of RC slabs in mitigating progressive collapse of building structures, Engineering Structures.

[19] Z. Huang, I. Burgess, R. Plank, Modeling Membrane Action of Concrete Slabs in Composite Buildings in Fire. II: Validations, Journal of Structural Engineering, 129, 1103-1112, 2003.

[20] Z. Huang, I. Burgess, R. Plank, Modeling Membrane Action of Concrete Slabs in Composite Buildings in Fire. I: Theoretical Development, Journal of Structural Engineering, 129, 1093-1102, 2003.

[21] C.G. Bailey, D.S. White, D.B. Moore, The tensile membrane action of unrestrained composite slabs simulated under fire conditions, Engineering Structures, 22, 1583-1595, 2000.

[22] S. Selamet, M. Garlock, Guidelines for Modeling Three Dimensional Structural Models using Finite Element Methods, in: International Symposium "Steel Structures: Culture \& Sustainability 2010", Istanbul, Turkey, 2010.

[23] J.A. Main, F.H. Sadek, Modeling of Bolted Connections for Collapse Analysis of Steel Structures, in: 14th International Symposium on Interaction of the Effects of Munitions with Structures, Seattle, WA, 2011.

[24] C.O. Rex, S.W. Easterling, Behavior and Modeling of Bolt Bearing on a Single Plate, Journal of Structural Engineering, 129 (2003) 797-800.

[25] C.W. Lewitt, W.H. Chesson Jr., W.H. Munse, Restraint characteristics of flexible riveted and bolted beam-to-column connections, in, University of Illinois, College of Engineering. 